\title{
Re-irradiation With Carbon Ion Radiotherapy for Pelvic Rectal Cancer Recurrences in Patients Previously Irradiated to the Pelvis
}

\author{
AMELIA BARCELLINI ${ }^{1 *}$, VIVIANA VITOLO ${ }^{1 *}$, LORENZO COBIANCHI ${ }^{2,3}$, ANDREA PELOSO $^{4,5}$, \\ ALESSANDRO VANOLI ${ }^{6}$, ALFREDO MIRANDOLA ${ }^{1}$, ANGELICA FACOETTI ${ }^{1}$, MARIA ROSARIA FIORE ${ }^{1}$, \\ ALBERTO IANNALFI ${ }^{1}$, BARBARA VISCHIONI ${ }^{1}$, FRANCESCO CUCCIA $^{7}$, SARA RONCHI ${ }^{1}$, \\ MARIA BONORA ${ }^{1}$, GIULIA RIVA ${ }^{1}$, RACHELE PETRUCCI ${ }^{1}$, EMMA D'IPPOLITO ${ }^{1}$, \\ FRANCESCA DAL MAS ${ }^{8,9}$, LORENZO PREDA $^{1,2}$ and FRANCESCA VALVO ${ }^{1}$ \\ ${ }^{I}$ National Center of Oncological Hadrontherapy (Fondazione CNAO), Pavia, Italy; \\ ${ }^{2}$ Department of Clinical-Surgical, Diagnostic and Pediatric Sciences, University of Pavia, Pavia, Italy; \\ ${ }^{3}$ General Surgery, Fondazione IRCCS Policlinico San Matteo, Pavia, Italy; \\ ${ }^{4}$ Division of Abdominal Surgery, Department of Surgery, Faculty of Medicine, \\ University of Geneva, Geneva, Switzerland; \\ ${ }^{5}$ HepatoPancreato-Biliary Centre, Geneva University Hospitals, Geneva, Switzerland; \\ ${ }^{6}$ Anatomic Pathology Unit, Department of Molecular Medicine, \\ University of Pavia and Fondazione IRCCS Policlinico San Matteo, Pavia, Italy; \\ ${ }^{7}$ School of Radiation Oncology, University of Palermo, Palermo, Italy; \\ ${ }^{8}$ Lincoln International Business School, University of Lincoln, Lincoln, U.K.; \\ ${ }^{9}$ Department of Law and Economics of Productive Activities, Sapienza University of Rome, Rome, Italy
}

\begin{abstract}
Background/Aim: Re-irradiation of locally recurrent rectal cancer poses challenges due to the proximity of critical organs, such as the bowel. This study aimed at evaluating the safety and efficacy of re-irradiation with Carbon Ion Radiotherapy (CIRT) in rectal cancer patients with local recurrence. Patients and Methods: Between 2014 and 2018, 14 patients were treated at the National Center of Oncological Hadrontherapy (CNAO Foundation) with CIRT for locally recurrent rectal cancer. Results: All patients concluded the treatment. No $G \geq 3$ acute/late reaction nor pelvic infections were observed. The 1-year and 2-year local control rates were, $78 \%$ and $52 \%$, respectively, and relapse occurred close to the bowel in 6 patients. The 1-year and 2-year overall survival
\end{abstract}

This article is freely accessible online.

*These Authors contributed equally to this work.

Correspondence to: Amelia Barcellini, Fondazione CNAO, Strada Campeggi 53, Pavia, Italy. Tel: +39 0382078455, Fax: +39 0382078903,e-mail: Amelia.Barcellini@cnao.it

Key Words: Rectal cancer recurrence, carbon ion radiotherapy, reirradiation. rates were $100 \%$ and $76.2 \%$ each; while the 1-year and 2-year metastasis free survival rates were $64.3 \%$ and $43 \%$. Conclusion: CIRT as re-irradiation for locally recurrent rectal cancer emerges as a safe and valid treatment with an acceptable rate of morbidity of surrounding healthy tissue.

Colorectal cancer (CRC) represents the third most frequent cancer worldwide, leading to the fourth most common cause of cancer deaths (1). Tumor stage is the most important prognostic factor; the five-year survival is about $90 \%$ for cancers confined to the primary site, $71 \%$ in those with local node involvement, and 14\% for Stage IV cancers (2).

The treatment standard for patients with CRC relies upon on the initial staging and encompasses a multimodal approach (surgical resection and radiotherapy in addition to chemotherapy). Complete tumor resection is necessary for a curative treatment approach and consists of trans-anal microscopic surgery for $\mathrm{T} 1$ lesions and anterior resection for $\mathrm{T} \geq 2$ tumor $(3,4)$.

For stage II-III tumors, pre-operative radio-chemotherapy has been shown to be superior to post-operative radiotherapy with a lower rate of local failure $(13 \%$ vs. $6 \%)(4,5)$.

In both the pre- and post-operative radiotherapy, doses of 45 Gy with a boost of 5.4 to 9 Gy to the macroscopic tumor or tumor bed is delivered. Also, radiotherapy administered 
in a short course $(25 \mathrm{~Gy}, 5 \mathrm{~Gy} /$ fraction) has been reported to cause a significant reduction in local recurrence $(4,6)$.

The risk of local recurrence after a curative treatment depends on pathological tumor/node/metastasis (TNM) stage (3), circumferential resection margin status, number of pathological lymph nodes, extracapsular invasion, extranodal deposits, tumor differentiation, lymph-vascular invasion, extramural vascular invasion, and perineural invasion $(4,7,8)$.

The multimodal approach plays a critical role in reducing the risk of locoregional recurrence. Most recurrences occur within the radiation field or at margins of radiation field; $78 \%$ of them are typically located in the low pelvic and presacral regions (9).

According to the European Society of Medical Oncology (ESMO) guidelines, the operable local recurrences could be treated with preoperative radiotherapy (standard dose of radiotherapy in not previously irradiated patients; short course of radiotherapy followed by a fluoropyrimidine and oxaliplatin-based chemotherapy; re-irradiation using lower doses in previously irradiated patients) followed by salvage surgery performed by a specialist team because of the complications due to the loss of the normal anatomical planes. If salvage surgery is not an option, to appease the symptoms, ESMO recommends palliative treatment, consisting of reirradiation at the lowest dose, systemic chemotherapy, brachytherapy, and palliative surgical diversion (4).

However, local recurrences are generally resistant to conventional treatments. For this reason, carbon ion radiotherapy (CIRT) may represent a valid alternative treatment with curative intent. CIRT, in comparison with conventional X-ray radiotherapy, has the advantage of primary physical selectivity in releasing the dose to the tumor with minimal surrounding tissue damage. Moreover, CIRT offers biological benefits by inducing complex double-strand breaks in DNA, leading to irreversible cell devastation despite cell cycle phase or oxygenation status. CIRT provides, with respect to photons, an increased relative biological effectiveness (RBE), which may be estimated amid 2 and 5 depending on the cell line as well as the endpoint analyzed (10-12).

Previous Japanese studies used CIRT for treatment of rectal cancer recurrences in patients not previously irradiated. Such experience highlighted exceptional local control rates superior to conventional radiation therapy, which could be considered a potential alternative to surgery alone (13).

The Heidelberg experience using CIRT for local recurrence of $\mathrm{CRC}$ in patients previously irradiated is also promising, and reveals only mild toxicity (14).

\section{Patients and Methods}

This retrospective study aimed to evaluate the safety and efficacy of re-irradiation with CIRT in patients with local recurrence of rectal cancer. The records of 14 patients with locally recurrent CRC were
Table I. Patient, tumor and treatment characteristics.

\begin{tabular}{|c|c|}
\hline & Value \\
\hline Number & 14 \\
\hline \multicolumn{2}{|l|}{ Gender (number) } \\
\hline Male & 12 \\
\hline Female & 2 \\
\hline \multicolumn{2}{|l|}{ Age, years } \\
\hline Median (range) & $58.5(34-78)$ \\
\hline \multicolumn{2}{|c|}{$\begin{array}{l}\text { Dose of prior EBRT } \\
\text { (at time of first diagnosis) }\end{array}$} \\
\hline Median (range) & 45 Gy $\left(45-76^{*}\right)$ \\
\hline \multicolumn{2}{|c|}{$\begin{array}{l}\text { Dose of prior BT boost } \\
\text { (at time of first diagnosis) }\end{array}$} \\
\hline Total dose (1 patient) & $20 \mathrm{~Gy}$ \\
\hline \multicolumn{2}{|c|}{ Dose of prior Re-irradiation } \\
\hline Total dose (1 patient) & $30 \mathrm{~Gy}$ \\
\hline \multicolumn{2}{|c|}{ Interval between EBRT and CIRT, months } \\
\hline Median (range) & $65(14-139)$ \\
\hline \multicolumn{2}{|l|}{ Relapse site } \\
\hline Pre-sacral & 10 \\
\hline Perineal & 1 \\
\hline Perianal & 1 \\
\hline Pre-coccygeal & 2 \\
\hline \multicolumn{2}{|l|}{ GTV volume, $\mathrm{ml}$} \\
\hline Median (range) & $154.63(7.21-359.94)$ \\
\hline \multicolumn{2}{|l|}{ PTV volume, ml } \\
\hline Median (range) & $306.7(53.55-742.64)$ \\
\hline \multicolumn{2}{|l|}{ Total dose of CIRT } \\
\hline Median (range) & 60 Gy RBE (35-76.8) \\
\hline \multicolumn{2}{|l|}{ Dose for fraction (CIRT) } \\
\hline Median (range) & 3 Gy RBE (3-4.8) \\
\hline \multicolumn{2}{|l|}{ Number of fraction (CIRT) } \\
\hline Median (range) & $16(15-20)$ \\
\hline
\end{tabular}

EBRT: External beam radiotherapy; BT: brachytherapy; CIRT: carbon ion radiotherapy; RBE: relative biological effectiveness; *76 Gy dose delivered for prostatic cancer.

retrospectively reviewed. All patients underwent CIRT for CRC recurrence at the National Center of Oncological Hadrontherapy (CNAO Foundation) in Pavia, Italy.

The treatment planning of the recurrent disease was defined for each patient following an extensive discussion among the working group. Healthcare professionals involved included surgeons, oncologists and radiation oncologists, within a multidisciplinary team approach (15). All team members ensured effective knowledge translation flows (16), employing tools like in-person meetings (17), electronic medical records (18), evidence-based methods (19), clinical cases and best practices (19) and self-assessment (20).

All patients had inoperable lesions and had previously undergone photon therapy. All patients went through staging with total body computed tomographic (CT) scan to exclude distant metastasis and a pelvic magnetic resonance imaging (MRI) to study local disease extension.

CIRT was delivered using synchrotron-based scanning carbon ion beams (pencil beam scanning and spill-by-spill active energy variation). The technical delivery system details have been previously reported (21-23). 

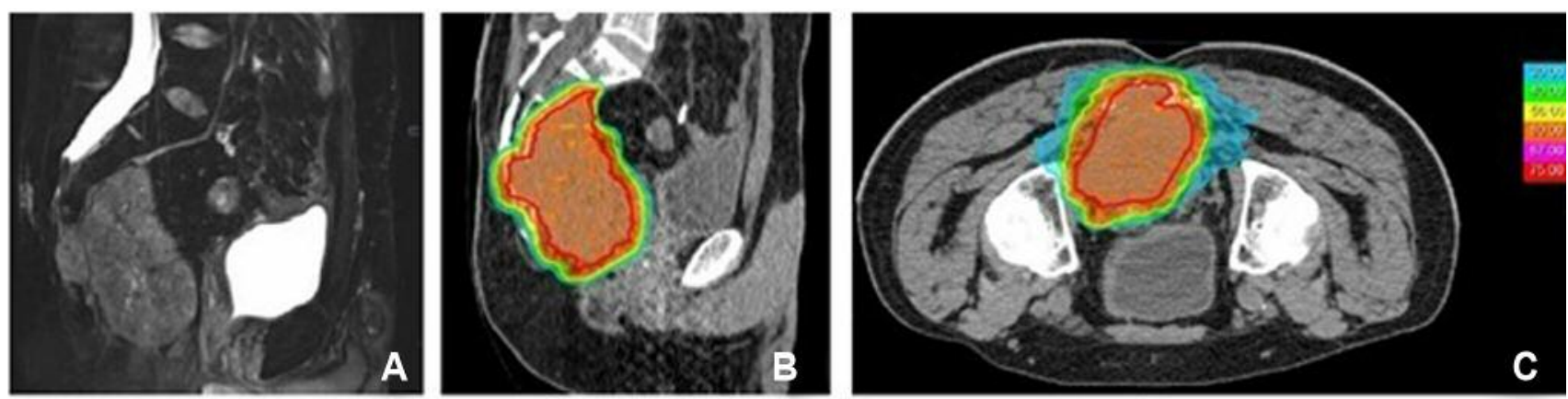

Figure 1. Dose distribution of CIRT. A case of local recurrence of rectal cancer. (A) Tumor extension defined in T2 weighted MRI scan. (B, C). Planning CT scan with typical steep gradient of dose distribution of carbon ion radiotherapy; red area represents the prescription dose of 60 GyRBE, while the light blue area over the edge of the tumour represents the dose of 30 GyRBE.

According to the center's institutional protocol, the following steps were employed $(24,25)$ :

The patient was restrained in the prone position, wearing a customized body thermoplastic mask. In that position, the healthcare professional gathered the planning images ( $2 \mathrm{~mm}$-thickness CT and contrast-enhanced MRI);

CE-marked Syngo RT treatment planning system (made by Siemens AG Healthcare, Erlangen, Germany; version C13) was used for plan optimization and estimation of RBE-weighted dose distributions;

Following prescription dosage and fractionation scheme in compliance with the National Institute of Radiological Sciences (Chiba, Japan), the dose conversion model mentioned above was applied $(18,19)$; dose counting was executed in line with the local effect model (LEM) version I exploiting the subsequent parameters: 1) $\alpha \gamma=0.1 \mathrm{~Gy}-1$; 2) $\beta \gamma=0.05 \mathrm{~Gy}-2$; 3) $\mathrm{Dt}=30 \mathrm{~Gy}$; and 4) nuclear radius $=5 \mu \mathrm{m}(26-27)$;

The approved plan was validated by a medical physicist (28);

The set-up was monitored at each treatment session employing two independent custom verification techniques. An infrared optical tracking system and a stereoscopic radiographic verification device were used (29); a six-degrees of freedom set-up correction vector was determined and remotely exerted to the treatment table.

Gross Tumor Volume (GTV) was defined as the area of contrast enhancement on T1-weighted MRI images. To take into account the microscopic spread, the clinical target volume (CTV) included the GTV with an added safety margin (from 5 to $10 \mathrm{~mm}$ ) depending on the different sites of recurrence and the clinical situation.

The planning target volume (PTV) was dependent on individual factors such as patient positioning or selected beam angles chosen and was CTV+3 and $10 \mathrm{~mm}$ of margin (30).

Regular follow-up, including clinical examination with scoring toxicity according to Common Terminology Criteria for Adverse Events version 4.0 (31) took place at our institution. Time-to-event data were calculated from the end of CIRT to last follow-up or death according to the Kaplan-Meier method. Local control (LC) was defined as no evidence of tumor regrowth in the PTV or absence of further tumor regrowth after best-treated lesion response. Local disease-free survival (l-DFS) was defined as the absence of locoregional failure. Metastasis progression-free survival (mPFS) was defined as the absence of distant failure.

\section{Results}

Patient and tumors characteristics are shown in Table I. The recurrent disease was presacral in 10 patients, perineal in 1 , perianal in 1 and pre-coccygeal in 2 cases. Patients' ages ranged between 34 and 78 years (median: 58.5 years), and the Karnofsky Performance Status was $>90$. There were twelve males and two females. All patients had a history of surgery and pelvic radiotherapy. Specifically, the dose of the previous radiotherapy ranged from 45 to $50.4 \mathrm{~Gy}$ in eleven patients, one of which received a brachytherapy boost up to a total dose of $20 \mathrm{~Gy}$. One patient with a local recurrence of CRC had been previously irradiated with a total dose of 76 Gy for prostate cancer. One patient, at the time of the first recurrence, underwent re-irradiation with stereotactic radiotherapy (30 Gy in six fractions). Before CIRT, four patients received spacer implantation via open surgery to create adequate distance between the bowel and the tumor (32). In three cases, an omental flap was used to create space between the tumor and the intestine, and in one case, a polytetrafluoroethylene (PTFE) prosthesis was placed. The median interval between the two courses of radiotherapy was 65 months (range=14-139 months). The median total CIRT dose was 60 Gy RBE (range=35-76.8) and was administered in a median number of 16 fractions (range $=15-20$ fractions) from 3 to 4.8 Gy RBE per fraction (Figure 1). The GTV ranged from 7.21 to $359.94 \mathrm{~cm}^{3}$, with a median of 154.63 $\mathrm{cm}^{3}$. The PTV ranged from 53.55 to $742.64 \mathrm{~cm}^{3}$ with a median of $306.7 \mathrm{~cm}^{3}$. All patients completed the scheduled treatment course.

The median follow-up was 18 months.

Overall acute toxicity was mild and observed in 3 cases: the most common acute toxicities were grade $2(\mathrm{G} 2)(7 \%)$ and G1 (14\%) neuropathic pain. The major late toxicities consisted of G2 peripheral neuropathy (14\%) after a median time of 9 months' post-treatment. 


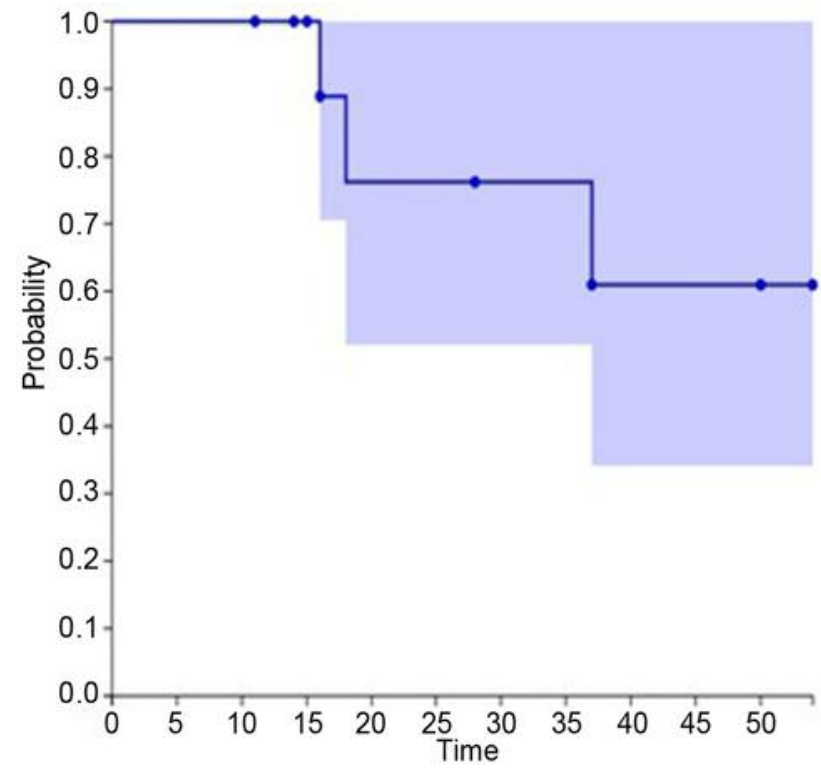

Figure 2. Overall survival. The 1-year and 2-year overall survival (OS) rates were $100 \%$ and $76.2 \%$, respectively (Kaplan-Meier plot).

Twelve months after CIRT, a sacral asymptomatic insufficiency fracture was observed. No $G \geq 3$ acute/late reaction or pelvic infections were observed. No acute or late $\mathrm{G}>1$ gastrointestinal side effects were reported; two patients complained about a G2 intermediate bladder toxicity that resolved with medications. Six patients experienced local progression after CIRT, five of whom in close proximity to the bowel, with a median local control (LC) of 14.5 months (range=2.4-49.5 months); seven patients were diagnosed with systemic progression with a median metastasis-free survival (m-PFS) of 14.4 (range $=2$ 40 months). In the entire series, the 1-year and 2-year LC were $78 \%$ and $52 \%$, respectively, the 1 -year and 2 -year mPFS rates were $64.3 \%$ and $43 \%$ and the 1-year and 2-year overall survival (OS) rates were $100 \%$ and $76.2 \%$, respectively (Figures 2 and 3 ).

\section{Discussion}

This was a retrospective study to evaluate the clinical outcome of re-irradiation with CIRT for local recurrence of CRC. Surgery, if indicated, is the treatment of choice for locally recurrent CRC. Recurring tumors in previously irradiated CRC areas were often located close to dose-limiting organs such as the intestinal tract. In case of previously high doses to organs at risk (OAR), when it was not possible to deliver doses with curative intent and stay within the OAR dose tolerance constraints, patients were treated with palliative care (chemotherapy or best support care). The palliation offered by

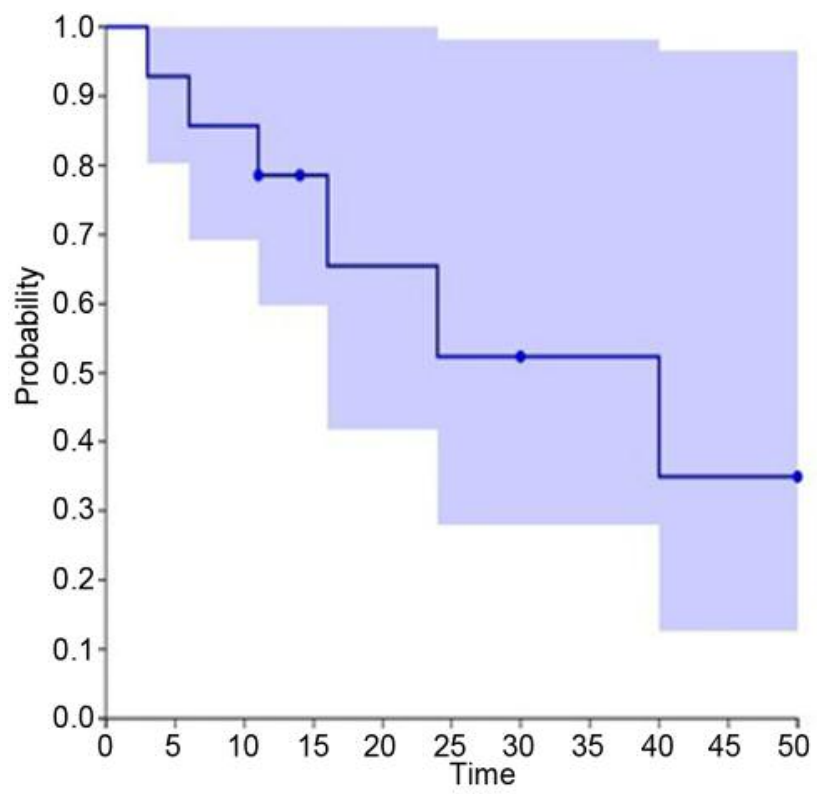

Figure 3. Local disease-free survival. The 1-year and 2-year LC were $78 \%$ and $52 \%$, respectively (Kaplan-Meier plot).

radiotherapy in addition to chemotherapy gives a modest survival benefit and a minimal chance of cure (4). Reports on re-irradiation with photon beam therapy for relapse of CRC are limited, and often radiotherapy is performed concurrently with systemic treatment.

In the Italian multicentric phase II study by the Study Group for Therapies of Rectal Malignancies (STORM), fiftynine patients with recurrent CRC underwent hyperfractionated chemoradiation (1.2 Gy twice a day up to a total dose of 30 Gy with concomitant infusion of 5-fluorouracil at the dose of $225 \mathrm{mg} / \mathrm{m}^{2}$ per day, seven days a week) and, four to six weeks after the end of chemoradiation, surgery was performed in resectable cases. At analysis, acute G3 gastrointestinal effects were reported in $5.1 \%$ of all cases but no G4 gastrointestinal toxicity was documented; the response rate after chemoradiation was $44.1 \%$ [95\% confidence interval $(\mathrm{CI})=29.0-58.9 \%]$, in $83.3 \%$ of all the cases symptomatic response (pain pelvic control) was observed and the resection was possible in 30 of 59 patients (50.8\%) (33).

Also, Tao et al. (28) and Sun et al. (29) have reported a good tolerance and adequate LC (better in patients who underwent second surgery) using hyperfractionation for the management of local relapse of CRC that had been previously irradiated. In both studies, severe acute grade $\geq 3$ gastrointestinal toxicities were described. In the large retrospective series of Tao et al. (34), the actuarial 3-year rate of grade 3-4 late toxicities was 34\% with a higher rate of $\mathrm{G}>3$ toxicity documented in surgical patients compared to those without surgery ( $54 \%$ versus $16 \%, p=0.001$ ). In the study of 
Sun et al. (35), acute toxicities, including grade 3-4 diarrhea $(9.7 \%)$ and late small bowel obstruction $(1.4 \%)$ were reported.

In the current experience, even though the tumor relapse was closer to the intestinal tract, all patients completed treatment safely, and no episodes of grade $\geq 2$ acute or late gastrointestinal toxicity caused by CIRT re-irradiation were experienced.

Besides the favourable dose distribution, CIRT has a variety of documented positive radiobiological features compared to photon radiotherapy, due to the characteristic microscopic distribution of energy deposition. The more considerable energy per particle transferred per unit distance by CIRT determines a higher probability of causing complex double-strand DNA breaks, leading to a more successful cell killing at the tumour site (36-38). The dosimetric and radiobiological properties of CIRT additively define high doses to the tumour saving at-risk adjacent healthy tissues. Therefore, CIRT could be advantageous for patients with radio-resistant $\mathrm{CRC}$ not reacted to prior conventional radiotherapy. The same applies when another treatment option is constrained by the adverse effects arising from previous radiotherapy. Different from the above-mentioned studies, in our cohort, temporary treatment interruption due to toxicity or patient lack of compliance was not needed, and all patients completed the scheduled treatment.

At the analysis of the Japanese experience, CIRT was well tolerated and offered a 5-year-LC and survival rates at 73.6 Gy RBE of $88 \%(95 \% \mathrm{CI}=80-93 \%)$ and $59 \%(95 \% \mathrm{CI}=50-$ $68 \%$ ), respectively (13).

Regardless, different from the current study, this large cohort of patients (186 treated lesions) did not receive prior radiotherapy, and often the toxicities occurred more frequently in previously irradiated patients. However, the Japanese results concerning LC and toxicity rates were better than those reported in other studies with comparable populations (locally recurrent CRC in patients never previously irradiated to the pelvis) (39). Most likely, the superiority was due to the better dose distribution and higher CIRT-related biological effects.

Habermehl et al. have reported the clinical outcome of 19 patients treated with single fractions of $3 \mathrm{~Gy}(\mathrm{RBE})$ with CIRT as re-irradiation of locally recurrent CRC. After a median follow-up of 7.8 months, four $(21 \%)$ local and three $(16 \%)$ systemic progressions with an estimated local progression of 20.6 months were described. Regarding toxicity, grade 2 gastrointestinal toxicities occurred in two patients, and no grade $\geq 3$ toxicities were experienced (14).

In agreement with the above-mentioned study, the CNAO experience showed a functional LC and mild toxicity. When the distance between the relapse and intestinal tract is not enough (at least $5 \mathrm{~mm}$ ), CIRT may be unsafe. In this case, patients must be evaluated to receive a surgical spacer placement that could create a sufficient distance from the organ at risk allowing tumor treatment with CIRT. In our series, four patients received spacer implantation by open surgery and a specialized surgical team without any complications.

Despite the limitations of the current study (including the retrospective nature of the data, the limited cohort, and the little follow-up) and considering the impact on clinical outcomes in terms of LC and toxicity, CIRT appears to be a promising, effective, and safe treatment option for the reirradiation of local recurrent CRC. After considering the mild toxicity, it would be compelling to evaluate concomitant chemotherapy during CIRT for the considered patients.

\section{Conclusion}

Re-irradiation with CIRT should be considered in the management of locally recurrent CRC in patients previously irradiated to the pelvis. However, further research is required to identify the long-term safety and efficacy enlarging the sample of treated patients.

\section{Conflicts of Interest}

The Authors have no conflicts of interest to declare regarding this study.

\section{Authors' Contributions}

All Authors approved the final version of the manuscript. FV conceived the idea for the study. AB: data curation, methodology, writing the original draft and editing; VV data collection and review, LC, AP, AV, FDM review and editing. AM: Methodology and review. AF: data collection and review. MRF, AI, BV, SR, GR, RP, ED, FC, LP: data collection.

\section{References}

1 Araghi M, Soerjomataram I, Jenkins M, Brierley J, Morris E, Bray $\mathrm{F}$ and Arnold M: Global trends in colorectal cancer mortality: projections to the year 2035. Int J Cancer 144(12): 2992-3000, 2019. PMID: 30536395. DOI: 10.1002/ijc.32055

2 SEER Cancer Stat Facts: Colorectal Cancer. National Cancer Institute. Available at: http://seer.cancer.gov/statfacts $/ \mathrm{html} /$ colorect.html [Last accessed on March 2, 2018]

3 Brierley JD, Gospodarowicz MK and Wittekind C: TNM Classification of Malignant Tumours, 8th edition. Oxford: John Wiley \& Sons, Inc., 2016.

4 Glynne-Jones R, Wyrwicz L, Tiret E, Brown G, Rödel C, Cervantes A and Arnold D; ESMO Guidelines Committee: Rectal cancer: ESMO Clinical Practice Guidelines for diagnosis, treatment and follow-up. Ann Oncol 29(Suppl 4): iv263, 2018. PMID: 29741565. DOI: 10.1093/annonc/mdy161

5 Sauer R, Becker H, Hohenberger W, Rödel C, Wittekind C, Fietkau R, Martus P, Tschmelitsch J, Hager E, Hess CF, Karstens JH, Liersch T, Schmidberger H, Raab R and German Rectal Cancer Study Group: Preoperative versus postoperative chemoradiotherapy for rectal cancer. N Engl J Med 351(17): 1731-1740, 2004. PMID: 15496622. DOI: 10.1056/NEJMoa 040694 
6 Sebag-Montefiore D, Stephens RJ, Steele R, Monson J, Grieve R, Khanna S, Quirke P, Couture J, de Metz C, Myint AS, Bessell E, Griffiths G, Thompson LC and Parmar M: Preoperative radiotherapy versus selective postoperative chemoradiotherapy in patients with rectal cancer (MRC CR07 and NCIC-CTG C016): a multicentre, randomised trial. Lancet 373(9666): 811-820, 2009. PMID: 19269519. DOI: 10.1016/S0140-6736(09)60484-0

7 Chand M, Siddiqui MR, Swift I and Brown G: Systematic review of prognostic importance of extramural venous invasion in rectal cancer. World J Gastroenterol 22: 1721-1726, 2016. PMID: 26819536. DOI: 10.3748/wjg.v22.i4.1721

8 Glimelius B, Tiret E, Cervantes A and Arnold D: ESMO Guidelines Working Group: Rectal cancer: ESMO Clinical Practice Guidelines for diagnosis, treatment and follow-up. Ann Oncol 24: vi81-88, 2013. PMID: 24078665. DOI: 10.1093/ annonc/mdt 240

$9 \mathrm{Yu}$ TK, Bhosale PR, Crane $\mathrm{CH}$, Iyer RB, Skibber JM, Rodriguez-Bigas MA, Feig BW, Chang GJ, Eng C, Wolff RA, Janjan NA, Delclos ME, Krishnan S and Das P: Patterns of locoregional recurrence after surgery and radiotherapy or chemoradiation for rectal cancer. Int J Radiat Oncol Biol Phys 71(4): 1175-1180, 2008. PMID: 24078665. DOI: 10.1016/ j.ijrobp.2007.11.018

10 Hall EJ and Giacca AJ: Radiobiology for the radiologist. Philadelphia, PA, USA, Lippincott Williams \& Wilkins, 2012.

11 Tsujii H, Kamada T, Shirai T, Noda K, Tsuji H and Karasawa K: Carbon-ion radiotherapy. Tokyo: Springer Science \& Business Media, pp. 127-309, 2013

12 Durante $M$ and Loeffler JS: Charged particles in radiation oncology. Nat Rev Clin Oncol 7: 37-43, 2010. PMID: 19949433. DOI: $10.1038 /$ nrclinonc.2009.183

13 Yamada S, Kamada T, Ebner DK, Shinoto M, Terashima K, Isozaki Y, Yasuda S, Makishima $\mathrm{H}$, Tsuji $\mathrm{H}$, Tsujii $\mathrm{H}$, Isozaki T, Endo S, Takahashi K, Sekimoto M, Saito N and Matsubara H; Working Group on Locally Recurrent Rectal Cancer: Carbon-ion radiation therapy for pelvic recurrence of rectal cancer. Int $\mathrm{J}$ Radiat Oncol Biol Phys 96(1): 93-101, 2016. PMID: 27375166. DOI: $10.1016 /$ j.ijrobp.2016.04.022

14 Habermehl D, Wagner M, Ellerbrock M, Büchler MW, Jäkel O, Debus $\mathbf{J}$ and Combs SE: Reirradiation using carbon ions in patients with locally recurrent rectal cancer at HIT: First results. Ann Surg Oncol 22(6): 2068-2074, 2015. PMID: 25384705. DOI: $10.1245 / \mathrm{s} 10434-014-4219-\mathrm{z}$

15 Karimi L, Dadich A, Fulop L, Leggat SG, Eljiz, K, Fitzgerald JA, Smyth A, Hayes KJ, and Kippist L: Brilliant health service management: challenging perceptions and changing $\mathrm{HR}$ practices in health services. Asia Pac J Hum Resour 57: 174-190, 2019. DOI: 10.1111/1744-7941.12189

16 Straus S, Tetroe J and Graham ID: Knowledge translation in health care: Moving from evidence to practice. BMJ Books, 2013.

17 D'Andreta D, Marabelli M, Newell S, Scarbrough H and Swan $\mathrm{J}$ : Dominant cognitive frames and the innovative power of social networks. Organ Stud 37(3): 293-321, 2016. DOI: 10.1177/ 0170840615613374

18 Baigorri A, Villadangos J, Astrain JJ and Córdoba A: A medical knowledge management system based on expert tagging (MKMST). In: Data Management and Security: Applications in Medicine, Sciences and Engineering. Bia A (eds.). Southampton, UK, WIT Press Vol 45, pp. 221-231, 2013. DOI: 10.2495/ DATA130201
19 Olson CA, Tooman TR and Alvarado CJ: Knowledge systems, health care teams, and clinical practice: a study of successful change. Adv in Health Sci Educ 15: 491-516, 2010. PMID: 20069357. DOI: 10.1007/s10459-009-9214-y

20 Fingrut W, Beck LA and Lo D: Oncology communities of practice: insights from a qualitative analysis. Curr Oncol 25(6): 378-383, 2018. PMID: 30607112. DOI: 10.3747/co.25.4088

21 Rossi S: The National Centre for Oncological Hadrontherapy (CNAO): Status and perspectives. Phys Med 31: 333-351, 2015. PMID: 25840619. DOI: 10.1016/j.ejmp.2015.03.001

22 Giordanengo S, Garella MA, Marchetto F, Bourhaleb F, Ciocca M, Mirandola A, Monaco V, Hosseini MA, Peroni C, Sacchi R, Cirio R and Donetti M: The CNAO dose delivery system for modulated scanning ion beam radiotherapy. Med Phys 42: 263275, 2015. PMID: 25563266. DOI: 10.1118/1.4903276

23 Mirandola A, Magro G, Lavagno M, Mairani A, Molinelli S, Russo S, Mastella E, Vai A, Maestri D, La Rosa V and Ciocca $\mathrm{M}$ : Characterization of a multilayer ionization chamber prototype for fast verification of relative depth ionization curves and spread-out-Bragg-peaks in light ion beam therapy. Med Phys 45(5): 2266-2277, 2018. PMID: 29537642. DOI: $10.1002 / \mathrm{mp} .12866$

24 Fossati P, Molinelli S, Matsufuji N, Ciocca M, Mirandola A, Mairani A, Mizoe J, Hasegawa A, Imai R, Kamada T, Orecchia $\mathrm{R}$ and Tsujii $\mathrm{H}$ : Dose prescription in carbon ion radiotherapy: A planning study to compare NIRS and LEM approaches with a clinically-oriented strategy. Phys Med Biol 57: 7543-7554, 2012. PMID: 23104051. DOI: 10.1088/0031$9155 / 57 / 22 / 7543$

25 Molinelli S, Magro G, Mairani A, Matsufuji N, Kanematsu N, Inaniwa T, Mirandola A, Russo S, Mastella E, Hasegawa A, Tsuji H, Yamada S, Vischioni B, Vitolo V, Ferrari A, Ciocca M, Kamada T, Tsujii H, Orecchia R and Fossati P: Dose prescription in carbon ion radiotherapy: How to compare two different RBEweighted dose calculation systems. Radiother Oncol 120: 307-312, 2016. PMID: 27394694. DOI: 10.1016/j.radonc. 2016.05.031

26 Krämer M and Scholz M: Treatment planning for heavy-ion radiotherapy: calculation and optimization of biologically effective dose. Phys Med Biol 45: 3319-33330, 2000. PMID: 11098906. DOI: $10.1088 / 0031-9155 / 45 / 11 / 314$

27 Barcellini A, Vitolo V, Facoetti A, Fossati P, Preda L, Fiore MR, Vischioni B,Iannalfi A, Bonora M, Ronchi S, D'Ippolito E, Petrucci R, Viselner G, Ciocca M,Valvo F and Orecchia R: Feasibility of carbon ion radiotherapy in the treatment of gynecological melanoma. In Vivo 33(2): 473-476, 2019. PMID: 30804128. DOI: 10.21873 /invivo. 11497

28 Molinelli S, Mairani A, Mirandola A, Vilches Freixas G, Tessonnier T, Giordanengo S, Parodi K, Ciocca M and Orecchia R: Dosimetric accuracy assessment of a treatment plan verification system for scanned proton beam radiotherapy: oneyear experimental results and Monte Carlo analysis of the involved uncertainties. Phys Med Biol 58: 3837-3847, 2013. PMID: 23681116. DOI: 10.1088/0031-9155/58/11/3837

29 Pella A, Riboldi M, Tagaste B, Bianculli D, Desplanques M, Fontana G, Cerveri P, Seregni M, Fattori G, Orecchia R and Baroni G: Commissioning and quality assurance of an integrated system for patient positioning and setup verification in particle therapy. Technol Cancer Res Treat 13: 303-314, 2014. PMID: 24206209. DOI: $10.7785 /$ tcrt 2012.500386 
30 Combs SE, Kieser M, Habermehl D, Weitz J, Jäger D, Fossati P, Orrechia R, Engenhart-Cabillic R, Pötter R, Dosanjh M, Jäkel $\mathrm{O}$, Büchler MW and Debus J: Phase I/II trial evaluating carbon ion radiotherapy for the treatment of recurrent rectal cancer: the PANDORA-01 trial. BMC Cancer 12: 137, 2012. PMID: 22472035. DOI: $10.1186 / 1471-2407-12-137$

31 National Cancer Institute: Common Terminology Criteria for Adverse Events (CTCAE), Version 4.0. Available at: http://evs.nci.nih.gov/ftp1/CTCAE/About.html [Last accessed on 27 September 2018]

32 Cobianchi L, Peloso A, Vischioni B, Panizza D, Fiore MR, Fossati P, Iannalfi A, Ciocca M, Brugnatelli S, Dominioni T, Bugada D, Maestri M, Alessiani M, Valvo F, Orecchia R and Dionigi P: Surgical spacer placement prior carbon ion radiotherapy (CIRT): an effective feasible strategy to improve the treatment for sacral chordoma. World J Surg Oncol 12: 14(1): 262, 2016. PMID: 27507254. DOI: 10.1186/s12957-016-0966-6

33 Valentini V, Morganti AG, Gambacorta MA, Mohiuddin M, Doglietto GB, Coco C, De Paoli A, Rossi C, Di Russo A, Valvo F, Bolzicco G and Dalla Palma M; Study Group for Therapies of Rectal Malignancies (STORM): Preoperative hyperfractionated chemoradiation for locally recurrent rectal cancer in patients previously irradiated to the pelvis: A multicentric phase II study Int J Radiat Oncol Biol Phys 64(4): 1129-1139, 2006. PMID: 16414206. DOI: $10.1016 /$ j.jrobp.2005.09.017

34 Tao R, Tsai CJ, Jensen G, Eng C, Kopetz S, Overman MJ, Skibber JM, Rodriguez-Bigas M, Chang GJ, You YN, Bednarski BK, Minsky BD, Delclos ME, Koay E, Krishnan S, Crane CH and Das P: Hyperfractionated accelerated reirradiation for rectal cancer: An analysis of outcomes and toxicity. Radiother Oncol 122(1): 146151, 2017. PMID: 28057329. DOI: 10.1016/j.radonc.2016.12.015.
35 Sun DS, Zhang JD, Li L, Dai Y, Yu JM and Shao ZY: Accelerated hyperfractionation field-involved re-irradiation combined with concurrent capecitabine chemotherapy for locally recurrent and irresectable rectal cancer. Br J Radiol 85(1011): 259-264, 2012. PMID: 21385917. DOI: $10.1259 / \mathrm{bjr} / 28173562$

36 Facoetti A, Barcellini A, Valvo F and Pullia M: The role of particle therapy in the risk of radio-induced second tumors: A review of the literature. Anticancer Res 39(9): 4613-4617, 2019. PMID: 31519558. DOI: 10.21873/anticanres.13641

37 Barcellini A, Vitolo, V, Mastella E, Mirandola A and Valvo F: Letter to the Editor concerning "Re-irradiation in gynaecological cancers, present experiences and future hopes". J Radiat Oncol 8: 355-356, 2019. DOI: 10.1007/s13566-019-00396-w

38 Belli M, Campa G, Simone G, Tabocchini MA, Ballarini F, Facoetti A and Ottolenghi A: Radiobiological basis of hadrontherapy. Rivista Medica 14(1): 31-42, 2008.

39 Cai G, Zhu J, Palmer JD, Xu Y, Hu W, Gu W, Cai S and Zhang Z: CAPIRI-IMRT: A phase II study of concurrent capecitabine and irinotecan with intensity-modulated radiation therapy for the treatment of recurrent rectal cancer. Radiat Oncol 10: 57, 2015. PMID: 25889149. DOI: 10.1186/s13014-015-0360-5
Received March 9, 2020

Revised March 20, 2020

Accepted March 24, 2020 